\title{
Correction to: Formal Approaches to Semantics and Pragmatics
}

Elin McCready, Katsuhiko Yabushita and Kei Yoshimoto

\section{Correction to:}

E. McCready et al. (eds.), Formal Approaches to Semantics

and Pragmatics, Studies in Linguistics and Philosophy, DOI 10.1007/978-94-017-8813-7

This book was inadvertently published with the incorrect author name. "Eric McCready" has been corrected as "Elin McCready". This has now been amended throughout the book. 